\title{
Explorando quantitativamente observações feitas com espectrógrafos caseiros por meio de recursos digitais
}

Exploring observations made with home spectrographs quantitatively using digital resources

\author{
Jéssica Pereira Santos ${ }^{*}$, Sergio Scarano Jr10 \\ ${ }^{1}$ Universidade Federal de Sergipe, Departamento de Física, São Cristóvão, SE, Brasil.
}

Recebido em 07 de junho de 2021. Aceito em 10 de junho de 2021.

\begin{abstract}
Neste trabalho expomos um método para obter calibrações em comprimento de onda de espectros para os quais não se conhece previamente as linhas espectrais, aplicando-a em uma atividade didática prática utilizando espectros obtidos de espectrógrafos caseiros. Apresentamos a configuração instrumental para obtenção simultânea dos espectros de interesse e de calibração. Com os espectros registrados aplicamos técnicas de processamento de imagens para tratar, otimizar a extrair os dados de interesse. Para o procedimento de calibração indicamos como pesquisar pelos valores padrões no banco de dados de linhas espectrais do NIST. Uma planilha eletrônica foi elaborada com o propósito de ilustrar o processo de calibração dos espectros por meio de procedimentos usando o software DS9. Demonstramos a aplicação do procedimento de calibração nos espectros unidimensional e bidimensional no caso do espectro de lâmpada de vapor de hélio, com a qual recuperamos o comprimento de onda das linhas espectrais com resíduos inferiores a $4 \mathrm{~nm}$. Por fim apresentamos sugestões de algumas atividades didáticas práticas que podem ser conduzidas por meios dos procedimentos aqui expostos utilizando observações de fontes luminosas do cotidiano.
\end{abstract}

Palavras-chave: Ensino de Física, calibração, espectros, quantitativo.

In this work, we show a method to obtain wavelength calibrations from a standard source to be applied to spectra for which spectral lines are unknown, in order to use them in didactic activities involving homemade spectrographs. We present the instrumental setup used to obtain the calibration and the spectra of interest simultaneously. With the spectra, we show how to apply image processing techniques to treat, optimize and extract the data. For the calibration procedure we indicate how to search for the default values in the NIST spectral line database. An electronic spreadsheet was elaborated to obtain the spectra calibration by means of procedures using the DS9 software. We demonstrate the application of the calibration procedure in unidimensional and bidimensional spectra in the case of the helium vapor lamp spectrum with which we recover the wavelength of spectral lines with residues below $4 \mathrm{~nm}$. Finally, we present suggestions for some practical didactic activities that can be conducted by means of the procedures exposed here using observations from everyday light sources. Keywords: Physics teaching, astronomy teaching, spectra, quantitative approach.

\section{Introdução}

Uma vez que a cor enxergada por cada pessoa é uma grandeza subjetiva, o único modo de quantificá-la objetivamente é conhecendo a sua frequência ou comprimento de onda. A cor de um objeto é resultado da parte de radiação eletromagnética visível que ao incidir sobre ele, não é absorvida. Já a cor que enxergamos um objeto depende da cor da luz incidente no objeto e das células do fundo de nossa retina. É este último aspecto que pode gerar polêmicas entre as cores [1] e o que faz com que uma pessoa daltônica possua uma percepção distinta de cor em relação a maioria das pessoas. A faixa da luz visível que ilumina os objetos à nossa volta é composta por de ondas eletromagnéticas caracterizadas por suas frequências $f$ ou comprimentos de onda $\lambda$. Contudo, um feixe de luz que aparenta ser amarelo, como a luz

\footnotetext{
*Endereço de correspondência: jpereirafisica@gmail.com
}

do Sol, pode conter ondas com inúmeras frequências e diferentes intensidades que podem ser identificadas individualmente através de uma análise de seu espectro luminoso.

Apesar dos fenômenos luminosos serem parte de nossa experiência cotidiana, sua natureza apresenta aspectos que em muito fogem do senso comum e ao se tratar da caracterização de cores, estes aspectos podem ser perdidos na subjetividade da visão. Neste ponto, os trabalhos que abordam a observação qualitativa de espectros, contém potencialmente esta subjetividade.

$\mathrm{Na}$ literatura encontram-se diversos trabalhos abordando, de forma demonstrativa, a espectroscopia de fontes luminosas de fácil obtenção para aplicação em experimentos escolares [2] [4. Estes trabalhos trazem análises qualitativas da luz. O teor quantitativo de análise espectrais em sala de aula foi abordado no início da década de 1990 [5, 6], quando poucos recursos digitais eram disponíveis. Nos últimos anos, técnicas de análise 
espectral realizadas com o uso de softwares tem sido cada vez mais implementadas, mas ainda são poucos os trabalhos que exploram aspectos quantitativos dos espectros (vide [7] 9]).

A análise quantitativa de espectros é a base de diversas áreas científicas, sendo a parte técnica para calibrar energia e a intensidade em cada faixa de energia fundamentalmente a mesma independentemente das áreas. Para calibração de um espectro é necessário comparar a resposta instrumental a alguma fonte de referência, para qual se define valores padrões. Da associação entre valores instrumentais e de calibração são feitas interpolações e extrapolações de modo a determinar as grandezas características de um espectro observado para uma fonte desconhecida.

Assim, em Química, por exemplo, pode-se submeter amostras de materiais às chamas de um bico de Bunsen e da luz emitida por estes, dispersada em um espectrógrafo, pode-se reconhecer qualitativamente as linhas espectrais características de um elemento, visto que o conjunto de emissões dele funciona como uma impressão digital do material. Mas raramente os materiais são puros e frequentemente as fontes de energia para produzir linhas espectrais podem não ser suficientes para excitar o material, ou, por outro lado, podem ser muito elevadas para completamente ionizá-los. Átomos hidrogenóides, por exemplo, podem ter espectros qualitativamente semelhantes entre si, mas é a medida quantitativa que vai permitir diferenciá-los. Isso é feito por meio de espectrômetros das mais diferentes naturezas, que quando calibrados adequadamente não apenas diferencia elementos, mas os quantifica com calibrações extremamente precisa feitas em análise quantitativa [10.

Em Física Quântica e Nuclear a determinação da emissão ou absorção dos elétrons em diferentes estágios de ionização, a partir de espectros propriamente calibrados, permite determinar as propriedades físicas dos átomos e dos núcleos - estruturas inacessíveis a observação direta, mas que deixam "assinaturas" nas energias de emissão e absorção observadas de cada elemento [11. Estas propriedades, combinadas em grandes quantidades de átomos com características eletrônicas especificas, são investigadas na Física de Materiais, reconhecida por investigar compostos com propriedades macroscópicas específicas. Exemplo disso são os semicondutores e as tecnologias associadas a eles, como os LEDs, que com suas emissões características, permitem construir dispositivos de exibição de imagens, ou os lasers, também com uma vasta gama de emissões em linhas características, com aplicações diversas, indo desde pinças ópticas [12] para manipular partículas, tecnologia para cirurgias ou procedimentos estéticos e até mesmo como "réguas" para medir a distância da Terra à Lua e testar o princípio de equivalência [13.

Em Biologia, macromoléculas não geram apenas linhas específicas, mas bandas inteiras que podem ser observadas em modo vibracional no infravermelho pela espectroscopia Raman, mas cujos comprimentos de onda apenas são acessíveis e caracterizados a partir de observações controladas de linhas espectrais conhecidas que servem como base de calibração [14].

A Astrofísica permite a caracterização detalhada de objetos celestes basicamente utilizando a espectroscopia, por meio da posição de linhas espectrais ou sua ausência, para identificar os tipos de objetos, sua composição, energia e temperatura, velocidade, campo magnético etc. Todas essas aplicações da espectroscopia na Astrofísica dependem primariamente de uma etapa observacional de calibração em comprimento de onda utilizando, no óptico, por exemplo, lâmpadas de mercúrio, argônio, cobre, ferro e até mesmo lasers, com linhas espectrais em número e energia bem conhecidas [15.

Por todos estes motivos, um trabalho que contemple os processos de calibração tem papel didático relevante no contexto de sala de aula tanto na educação básica quanto no ensino superior, pois, por um lado conecta interdisciplinarmente diversas áreas do conhecimento em um único processo, e por outro, permite fazer exercícios práticos específicos de acordo com a área de interesse, sendo o procedimento de quantificação meio para compreensão dos conceitos explorados.

Enfatizando estes aspectos didáticos, este artigo tem como objetivo apresentar um método para extrapolar a obtenção do valor numérico dos comprimentos de onda da luz dispersa por qualquer espectrógrafo, por meio de um procedimento de calibração de comprimento de onda. Pelo propósito didático utilizaremos um espectrógrafo caseiro e uma lâmpada de mercúrio como referência, que deve ser observada simultaneamente a outra fonte para qual se deseje conhecer os comprimentos de onda associados. Como recurso para análise dos espectros utilizaremos o software gratuito $S A O$ Image DS9 e referências do Institute of Standards and Technology (NIST) para identificação das linhas dos elementos que serão utilizados para calibração e comparação dos resultados. Apresentaremos o procedimento completo utilizando como exemplo a calibração em comprimento das linhas espectrais de uma lâmpada de hélio, a partir do que fizemos comparações detalhadas sobre a eficiência de nosso procedimento calibração. Exemplos de aplicação do procedimento são demonstrados em atividades envolvendo as linhas de cloreto de sódio na luz de uma vela, feixes de laser vermelho e verde, as bandas centrais da luz proveniente da tela de uma TV de LED e das linhas de absorção de Fraunhofer no espectro solar, independentemente do conhecimento de linhas espectrais nos espectros a serem analisados.

Dividimos este trabalho em quatro partes. Assim, após esta introdução, na segunda seção descreveremos o aparato experimental para obtenção de espectros calibráveis em comprimento de onda tomando como exemplo a observação das linhas de hélio e de mercúrio e apresentaremos os recursos digitais para uniformizar os espectros e estabelecer as linhas de referência por meio 
do NIST. Na terceira seção discutiremos o procedimento de calibração de comprimento de onda utilizando o DS9 e o reconhecimento das características espectrais dos espectros calibrados, tanto uni quanto bidimensionalmente. A quarta seção contém a descrição de algumas das possibilidades didáticas deste procedimento em exemplos úteis de extrapolação da calibração de comprimento de onda para fontes presentes no cotidiano. Ao final forneceremos algumas conclusões compilando os principais resultados referentes aos objetivos gerais, as perspectivas de trabalhos que podem ser derivadas e as atividades que podem ser promovidas com a exploração dos métodos apresentados aqui.

\section{Procedimento para Obtenção de Espectros Calibráveis}

O processo de calibração de um instrumento ou de uma medida envolve a comparação entre as leituras de um instrumento não calibrado que mede uma dada grandeza e os valores de referência dessa grandeza, a fim de estabelecer uma relação unívoca entre os dois sistemas, para tornar válida as medidas obtidas pelo instrumento.

Ao obtermos uma fotografia de um espectro de emissão ou absorção, é possível ver as raias espectrais e conhecer sua posição física na imagem, ou seja, a posição de cada raia, em píxeis. Entretanto, esta fotografia não é capaz de nos fornecer o comprimento de onda de cada faixa de energia antes de se realizar a calibração espectral. Este processo se dá ao compararmos este espectro com outro, que possui um conjunto de linhas cujos comprimentos de onda sejam conhecidos, e que tenha sido obtido com espectrógrafo na mesma configuração física (mesmo aparato experimental). Mais precisamente, na montagem de um espectroscópio, há uma distância entre a entrada de captação da luz e a rede de difração. Mantendo esta distância fixa e uma vez feita a calibração espectroscópica, esta se mantém válida para a identificação de linhas de novos espectros. Portanto, o fator determinante para a validade da calibração, é que o espectro da lâmpada de calibração e da luz a ser calibrada tenham sido obtidos com o aparato experimental exatamente e na mesma posição, visto que as posições relativas das raias espectrais nas fotografias serão diferentes. Para garantir essas condições, optamos pela obtenção dos dois espectros citados em uma mesma imagem. A Figura 1(f) traz um exemplo de um espectro obtido com essas especificações. É importante ressaltar que caso o espectroscópio seja fixo na câmera (e.g. [8]), bastará a obtenção de um único espectro de calibração e todos os demais espectros poderão utilizar o resultado desta calibração.

\subsection{Aparato experimental para a obtenção dos espectros calibráveis}

O aparato experimental usado neste trabalho é genérico e pode apresentar diversas variações [7.49]. O essencial

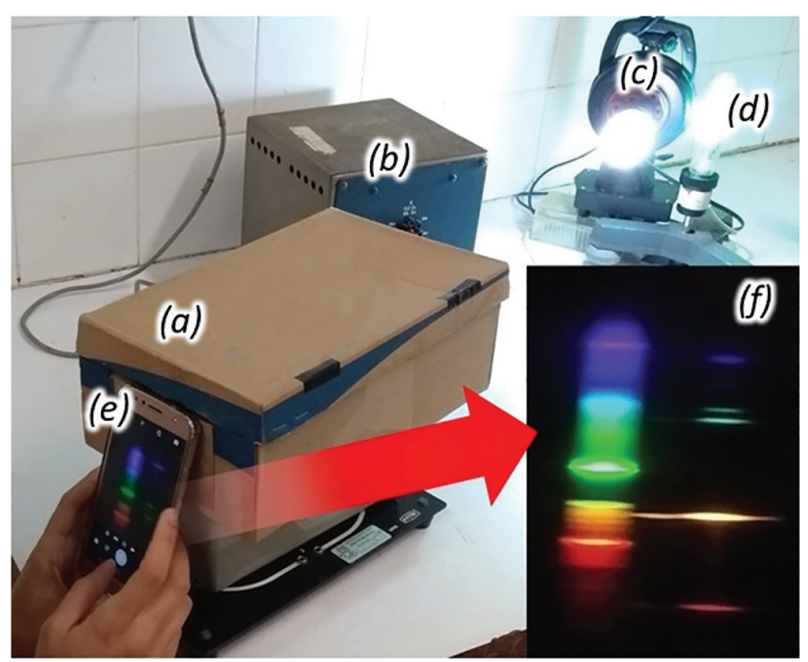

Figura 1: Exemplo de aparato experimental para obtenção de espectros de duas fontes luminosas em uma única fotografia. (a) Espectroscópio caseiro. (b) Fonte de alimentação da lâmpada de hélio. (c) Lâmpada fluorescente compacta (calibração). (d) Lâmpada de vapor de hélio (fonte de interesse). (e) Câmera fotográfica de um celular. (f) Espectro em detalhe obtido com o aparato aqui descrito: com duas fontes de luz, gerando um espectro com a lâmpada de calibração e a fonte de luz a ser calibrada (lâmpada de vapor de hélio).

é que através da fenda do espectrógrafo se possa obter uma imagem com os espectros de duas fontes distintas: uma das linhas espectrais conhecidas e outra da fonte a ser investigada, de modo que a câmera fotográfica, fixa ou aproximada da saída do espectroscópio, registre os dois espectros simultaneamente. O aparato experimental utilizado para a obtenção do espectro da lâmpada de hélio que calibramos neste trabalho é apresentado na Figura 1. sendo o espectroscópio construído com base no modelo descrito em [1]. Ele também foi usado para a aquisição dos espectros calibráveis disponível em nosso banco de espectros [16].

\subsection{O processo de retificação dos espectros}

Imagens de espectros obtidos com espectrógrafos caseiros são semelhantes ao da Figura 1(f). Desta forma, para que que a calibração seja feita corretamente, devemos corrigir os efeitos de perspectiva presentes nos espectros realizando a retificação destes. O processo visa garantir que o conjunto de linhas espectrais tenha cada qual, uma mesma disposição física na direção de dispersão espectral da imagem ( $\lambda$ na Figura 2), ou seja, uma mesma coordenada x ou y, dependendo da direção espacial ( $y$ na Figura 21. Com isto podemos garantir que disposição de todas as linhas mantenham, entre si, a mesma proporção que a promovida pela dispersão, sem efeitos geométricos de distorção. Sem esta correção, as posições relativas entre as linhas admitiriam soluções de calibração em comprimento de onda distintas em diferentes direções espaciais do espectro. 


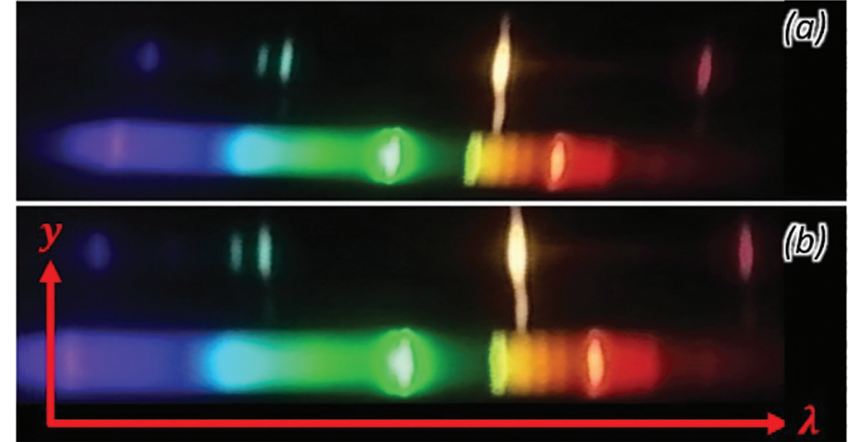

Figura 2: Espectro amostrando simultaneamente a lâmpada fluorescente de mercúrio para calibração e a lâmpada de vapor de hélio. (a) Espectro antes da retificação. (b) Espectro após a correção de perspectiva. As setas na cor vermelha indicam a direção de dispersão espectral da imagem no eixo horizontal $(\lambda)$ e a direção espacial, no eixo vertical (y).

Isso é feito, em termos digitais, por um conjunto de operações matriciais lineares do tipo:

$$
T(\vec{x})=\boldsymbol{A} \vec{x}
$$

em que $T(\vec{x})$ é a imagem resultante da aplicação da matriz de transformação $\boldsymbol{A}$, composta pelos elementos operacionais apropriados, sobre cada elemento da imagem original cujo fluxo encontra-se nas coordenadas do vetor $\vec{x}$. No caso particular para projeções em perspectiva, $\boldsymbol{A}$, além de conter operações que permitem transladar, rotacionar e redimensionar, condiciona estes efeitos a como cada ponto é representado sobre um plano em uma dimensão extra, considerando linhas que convergem para um centro de projeção a uma distância $d$, conforme [17], em que o elemento 1/d reduzirá as dimensões espaciais das demais coordenadas dependo da distância em relação a um ponto de fuga.

$$
\left[\begin{array}{c}
x \\
y \\
z \\
-\frac{z}{d}
\end{array}\right]=\left[\begin{array}{cccc}
1 & 0 & 0 & 0 \\
0 & 1 & 0 & 0 \\
0 & 0 & 1 & 0 \\
0 & 0 & -\frac{1}{d} & 0
\end{array}\right]\left[\begin{array}{c}
x \\
y \\
z \\
1
\end{array}\right]
$$

Combinada com as demais operações, $\boldsymbol{A}$ se reduz, para imagens bidimensionais, a uma matriz de transformação $3 \times 3$, suficiente para compensar as principais distorções dos espectros extraídos com os procedimentos apresentados na seção 2

Estas operações podem ser realizadas de uma forma mais simplificada por meio de alguns softwares de edição de imagem. No programa de fonte livre GIMP a matriz de transformação é exibida numericamente, permitindo entradas de valores de correção diretamente na matriz, ou ajustes utilizando o mouse.

Os procedimentos para retificação do espectro no GIMP são muito diretos.

Com a imagem bruta aberta, o usuário deve se concentrar em cinco ações básica.
(1) Recortar a zona de interesse do espectro;

(2) Aplicar transformações básicas separadamente, como por exemplo centrar ou rotacionar a imagem resultante do passo anterior;

(3) Estabelecer linhas de guia horizontal e vertical para orientar visualmente os limites de retificação. Isso é feito clicando-se e arrastando as guias geradas até posições estratégicas das imagens, como os limites inferior e superior e as próprias linhas espectrais.

(4) Acessar a ferramenta de transformação de perspectiva (Ferramentas $>$ Ferramentas de Transformação) e manusear a imagem por procedimentos de clicar e arrastar com o ponteiro do mouse em regiões da imagem, de modo a conciliar as distorções de tamanho e inclinação da imagem em perspectiva aos limites das linhas de guiagem.

(5) Por fim, com as próprias ferramentas disponíveis na Figura 3(b), pode-se recortar o espectro resultante para o procedimento de análise.

Uma demonstração detalhada do processo de retificação pode ser vista vídeo tutorial disponível em [18 onde, após a retificação, a imagem do espectro que antes era como na Figura 2(a), fica com mesmo referencial vertical para todas as linhas espectrais, como na Figura 2(b).

\subsection{Linhas espectrais de referência no NIST}

O NIST é uma agência governamental americana de metrologia que pesquisa padrões de medidas e de referências, fomentando o desenvolvimento e a divulgação de novas tecnologias. Um recurso muito útil disponibilizado por este instituto é um banco de dados de linhas de espectros atômicos, o "Atomic Spectra Database Lines" [19], no qual estão disponíveis os valores de comprimento de onda das linhas espectrais dos elementos químicos para diversos estados de excitação e ionização e informações complementares como intensidades, probabilidades de transição, as forças e tipo de transições além de gráficos para identificação de linhas, o espectro de Saha no equilíbrio termodinâmico local e os diagramas de Grotrian.

A consulta a este banco de dados é feita online, em uma interface simplificada, apresentada na Figura 4(a), mas que pode ser expandida pelo botão "Show Advanced Settings" para exibir opções avançadas de saída, onde se pode incluir novos critérios de pesquisa e incluir/delimitar parâmetros extras nos resultados de saída (Figura 4(b)). Também é possível expandir a interface de modo a exibir as opções que regulam os resultados gráficos. Por meio do botão "Show Graphical Options", serão expostas as opções que controlam os gráficos para identificação das linhas; alteram as informações que modificam as intensidades e larguras das linhas espectrais (considerando a condição de equilíbrio termodinâmico local de Saha) e permitem a geração 


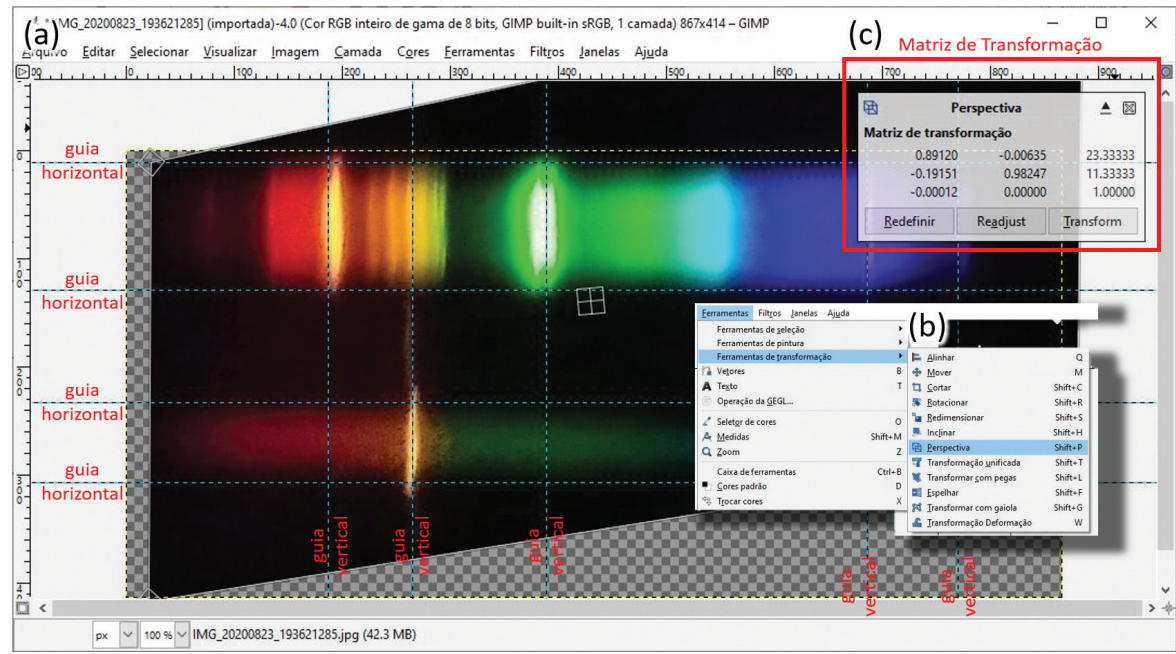

Figura 3: Detalhes do procedimento para retificação dos espectros com o GIMP. Em (a) a interface gráfica com a imagem aberta e já recortada, rotacionada e corrigida de perspectiva usando as funções de transformação acessadas no menu apresentado em (b). As linhas guias arrastadas a partir das réguas vertical e horizontal se sobrepõe às principais linhas espectrais e aos limites de largura e altura do espectro. Em (c) é apresentada a matriz de transformação numericamente.

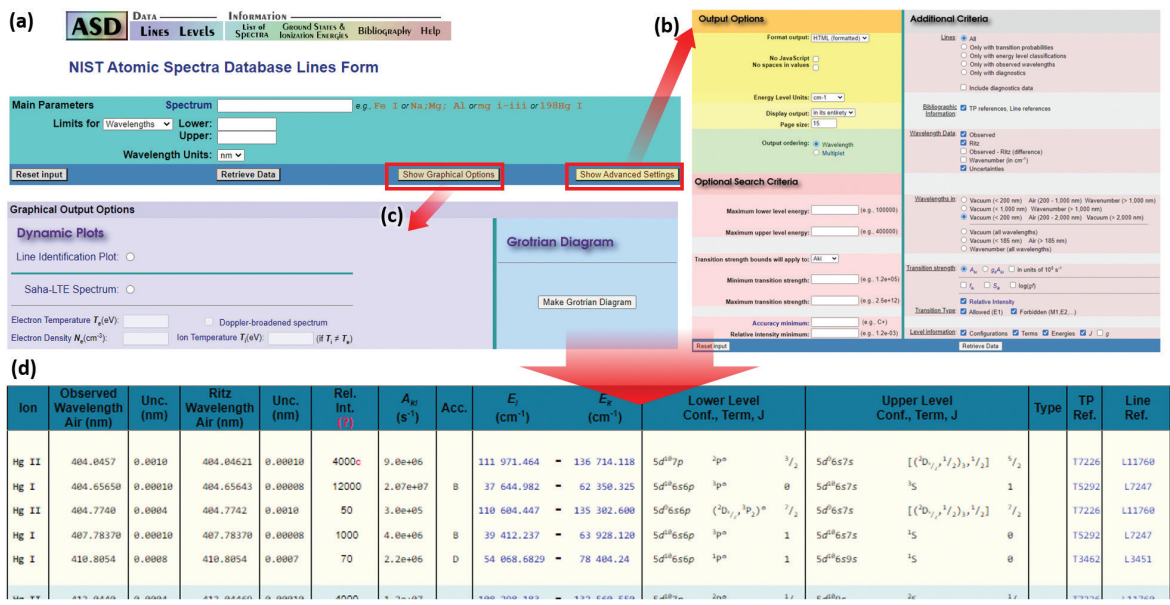

Figura 4: Configuração da página do NIST [19] para a identificação das linhas espectrais do mercúrio visíveis no espectro de uma lâmpada fluorescente. O quadro vermelho destaca o botão "Show Advanced Setting", que possibilita a visualização de uma série de filtros para refinar a busca.

dos diagramas de Grotrian para um estado de ionização específico (Figura 4(c)).

Para a busca dos valores de referência das linhas do mercúrio nos restringimos aos seguintes procedimentos:

(1) Inserimos na caixa de busca o símbolo de mercúrio $(\mathrm{Hg})$, sem restrição de estado de ionização, uma vez que diferentes lâmpadas podem excitar diferentes potências eletrônicos;

(2) Restringimos a faixa de emissão na região visível, que compreende comprimentos de onda entre 400 $\mathrm{nm}$ e $700 \mathrm{~nm}$;

(3) Refinamos a filtragem das linhas marcando a opção "Only with transitions probabilities" para que apenas as linhas geradas por transições com maior probabilidade sejam exibidas;
(4) Concluímos a pesquisas clicando em "Retrieve Data".

Com isso obtivemos as 66 linhas mais prováveis do mercúrio na região do espectro que compreende comprimentos de onda entre 400 e 700 nm (Figura 4(d)). Para cada linha são fornecidos o estado de ionização, os comprimentos de onda observados e calculados teoricamente com suas respectivas incertezas, as intensidades relativas, a probabilidade de transição espontânea, o índice de acurácia, as energias do nível superior e inferior, a notação espectroscópica dos subníveis energéticos, o termo de nível equivalente, o momento angular eletrônico total para os níveis inferior e superior e as referências para a probabilidade de transição sobre a linha espectral. 
Para os nossos propósitos, tomamos como referência a intensidade relativa das linhas. Este parâmetro expressa, em termos simples, a intensidade de cada linha espectral. Com base neste critério, selecionamos linhas espectrais com maior intensidade relativa em cada faixa de "cor" para identificar as linhas observadas.

Há de se levar em conta, no entanto, que em lâmpadas fluorescentes de vapor de mercúrio, parte significativa da emissão está na faixa do ultravioleta, que é, no entanto, "filtrada" antes de sair do bulbo da lâmpada, ao incidir na cobertura fluorescente, presente no revestimento interno do bulbo. As diferentes radiações emitidas, ao serem absorvidas pelo revestimento fluorescente, decaem quase instantaneamente (intervalo de tempo da ordem de $10^{-9} \mathrm{~s}$ ), com radiação distribuída a partir de níveis de energia ligeiramente menores que a emissão original, gerando a radiação visível observada. Neste fenômeno de fluorescência [20], dependendo da interação com o material do revestimento fluorescente e da energia dispendida para emissão de outros elementos presentes na composição das lâmpadas, a intensidade original das linhas próprias emitidas pelo mercúrio é afetada. Por isso, em nossa análise, para a seleção das linhas do mercúrio tomadas como referência para a calibração, não só a intensidade relativa, mas a capacidade das linhas consideradas de promoverem o melhor ajuste global de calibração foi considerado.

Recorrentemente vemos em sites na internet uma série de referências às linhas espectrais do mercúrio em espectros caseiros, com algumas incoerências entre as indicações dos valores de comprimento de onda de algumas delas [9, 21]. Neste trabalho selecionamos somente aquelas provenientes do NIST que minimizavam a dispersão residual entre os valores de referência do próprio NIST, obtidos por cálculos da teoria quântica, e os valores que obtivemos por meio da calibração. É possível verificar que algumas linhas observadas por [22], apresentam baixa intensidade relativa em comparação com linhas em comprimentos de onda próximos no NIST. Assumindo as últimas em relação as primeiras, considerando o argumento sobre a mudança das intensidades teóricas observadas, obtivemos ajustes com dispersões residuais menores, justificando, a escolha das linhas apresentadas como as referências que utilizaremos ao longo deste trabalho. Em geral as linhas desviantes em termos de suas intensidades consistem em exceções sem maiores impactos nos resultados aqui obtidos.

A Tabela 1 traz os comprimentos de onda das linhas espectrais de mercúrio tomadas como como padrão de calibração.

Como exemplo ilustrativo do processo de calibração utilizando uma lâmpada de mercúrio descrito neste trabalho, realizamos a calibração em comprimento de onda do espectro emitido por uma lâmpada de hélio com bulbo transparente (Figura 11(d)). Para a comparação dos resultados obtidos a partir das calibrações com os valores teoricamente esperados, fizemos uma nova pesquisa no NIST, segundo os mesmos critérios apresentados acima
Tabela 1: Linhas espectrais do Hg obtidas através do NIST e usadas para a calibração.

\begin{tabular}{lcl}
\hline Cor & $\lambda$ & Visibilidade \\
\hline Violeta & 404,77 & Alta (algumas lâmpadas) \\
Violeta & 407,78 & Alta (algumas lâmpadas) \\
Azul & 435,83 & Alta \\
Ciano & 485,56 & Alta (região larga) \\
Verde & 546,07 & (dupla) \\
Amarelo & 579,07 & Alta (dupla) \\
Laranja & 610,03 & Alta \\
Vermelho & 629,12 & Alta \\
Vermelho & 652,11 & Baixa \\
\hline
\end{tabular}

para o $\mathrm{Hg}$, mas aplicados ao $\mathrm{He}$. Os resultados são apresentados nas seções que se seguem.

\section{Procedimentos Digitais para Calibração em Comprimento de Onda}

\subsection{Utilizando o DS9 e uma planilha eletrônica para obtenção da equação de calibração}

Para realizar uma calibração válida, precisamos associar aos píxeis da imagem do espectro a uma grandeza física de referência, tomando como base as linhas espectrais da lâmpada de calibração. Isso pode ser feito a partir da correlação entre as medidas das posições instrumentais das linhas, em píxeis, e o comprimento de onda conhecido delas pelo NIST, o que fornece uma equação de calibração.

No procedimento aqui proposto usamos o software de visualização de imagens astronômicas DS9, sobre o qual detalhes podem ser encontrados em [23. Como material complementar, todos os procedimentos aqui realizados podem ser encontrados em vídeo tutoriais na playlist em 24. Para o registro das posições das linhas espectrais e obtenção da equação de calibração usamos uma planilha eletrônica disponível em [16].

Com o DS9 importamos a imagem em um dos formatos compatíveis. A imagem é aberta em tons de cinza, onde as posições horizontais das linhas representam o comprimento de onda e o tom de cinza a intensidade de luz (branco $=$ alta intensidade, preto $=$ baixa intensidade).

Para extrair o espectro unidimensional a partir da imagem bidimensional, ou seja, um gráfico com a intensidade de luz em função de uma grandeza associada à dispersão, habilitamos o modo de inserção de regiões DS9 (na opção Edit) e ativamos a opção Projection. Com ela é possível traçar uma linha sobre o espectro a partir da qual será extraído o fluxo sobre cada pixel que a linha cruza. Em nosso caso isto corresponde ao espectro unidimensional, sendo os picos de emissão ou os vales as linhas espectrais da fonte considerada. Fazemos isso primeiramente na região do espectro onde está localizada a dispersão da lâmpada de calibração. Para minimizar as flutuações de intensidade na direção espacial, expandimos a região amostrada clicando sobre 


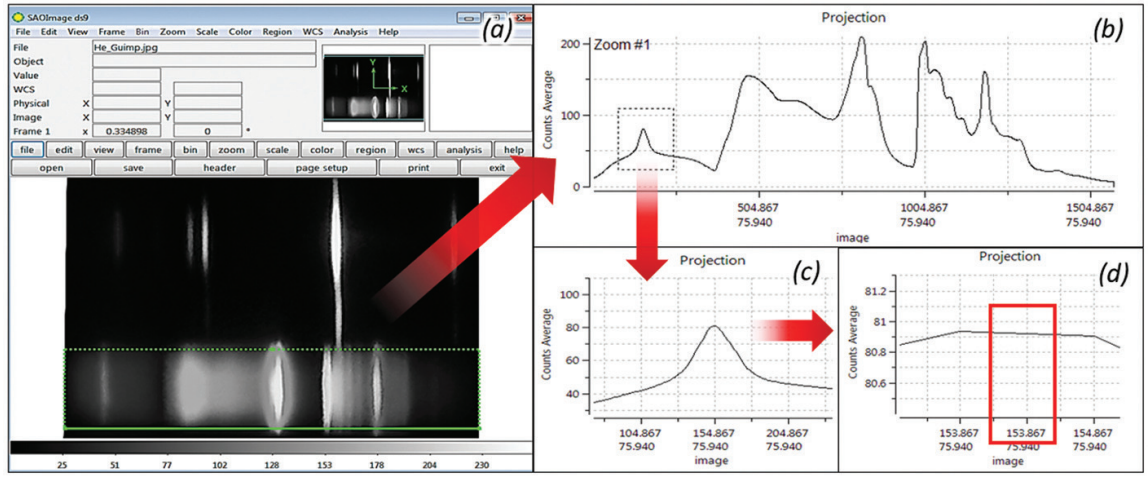

Figura 5: Procedimento para obtenção da coordenada instrumental de uma linha espectral. (a) Tela inicial do DS9 após aberto o espectro. Sobreposto ao espectro de calibração, em verde, está a região de projeção. (b) Espectro unidimensional extraído da região traçada e seleção da linha espectral de interesse. (c) Resultado do zoom no procedimento anterior. (d) Identificação do valor da coordenada, em pixel, correspondente ao centroide da linha espectral após mais procedimentos de zoom.

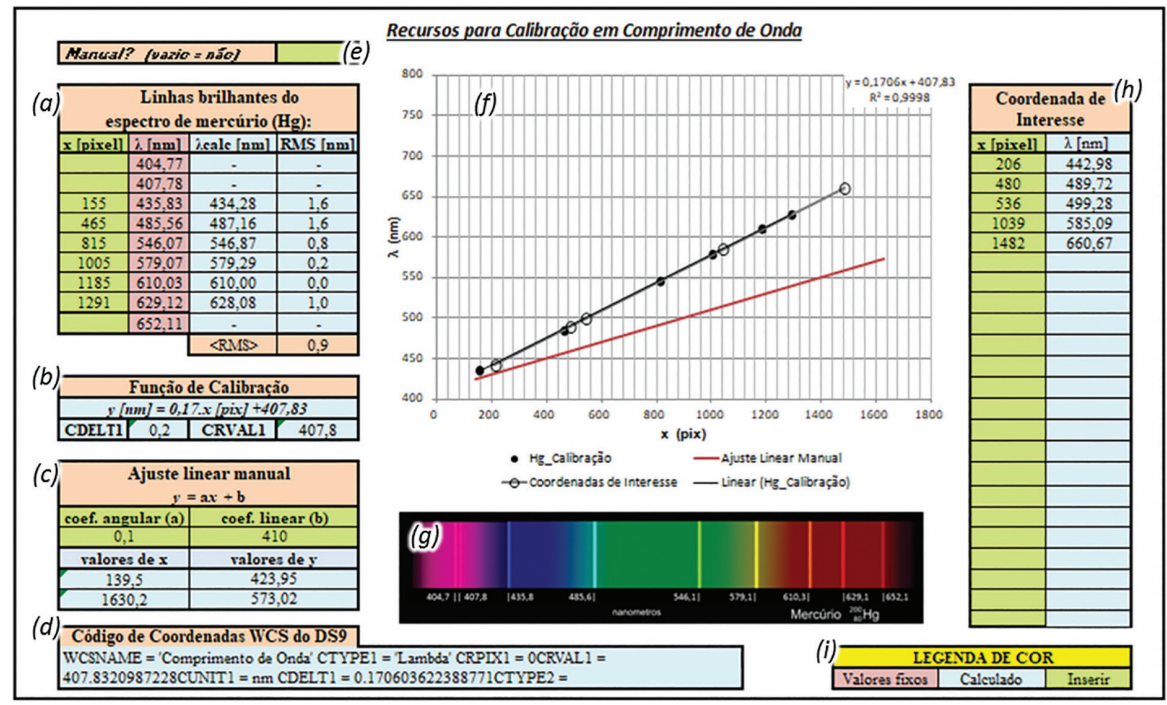

Figura 6: Imagem da planilha eletrônica disponível em [16]. (a) Tabela para a calibração do espectro da lâmpada de calibração. (b) Quadro com a função de calibração automática. (c) Quadro com calibração para um ajuste manual. (d) Seção que produz código de coordenadas WSC para realizar a calibração no espectro bidimensional (seção 3.4). (e) Célula que habilita a reta de ajuste manual. (f) Gráfico correlacionando as coordenadas instrumentais e sua correspondente em comprimento de onda. Nele a linha em negro representa o ajuste automático e em vermelho o ajuste manual. (g) Espectro bidimensional ilustrativo do mercúrio para auxiliar a identificação das linhas espectrais da fonte de calibração. (h) Tabela para verificar os resultados da calibração no espectro interesse, referentes, neste caso, às posições instrumentais das linhas do espectro do hélio. (i) Legenda de cores.

o ponto que aparece no centro da região traçada até a posição espacial onde se quer delimitar a extração do espectro considerado. Desse modo, veremos uma região selecionada, com formato retangular sobreposta ao espectro, como na metade inferior da Figura 5 (a).

Em algumas situações a ferramenta Projection no DS9 não exibe no gráfico os valores das posições dos píxeis no eixo horizontal. É possível contornar essa situação, dando um duplo clique na região verde selecionada e na janela que se abre, indicar o tipo de coordenadas como sendo Image.

Para identificar o centroide de cada linha, ampliamos no gráfico a região do pico, traçando um quadro de seleção em torno dele (Figura 5(b)). O gráfico resultante é o zoom do gráfico original dentro da região selecionada, como ilustrado na Figura 5(c). Este procedimento deve ser repetido até que seja possível ver na abcissa do gráfico a posição central do pixel (valor superior, $\mathrm{x}$ ) correspondente ao máximo de emissão da linha espectral (Figura 5(d)). O valor deve ser registrado na planilha eletrônica na coluna "Pixel" junto ao valor correspondente ao comprimento de onda na coluna " $\lambda$ ", (Figura 6(a)). O zoom é desfeito com cliques com o botão direito do mouse sobre gráfico e os mesmos procedimentos devem ser repetidos para cada linha espectral.

Seguimos a ordem de identificação dos picos das linhas espectrais da esquerda para a direita, o que representa, nos espectros que disponibilizamos em [16], iniciar da 
cor azul e seguir em direção ao vermelho, respeitando a ordem crescente de comprimentos de onda na planilha (Figura 6(a)). A planilha serve para qualquer espectro, independentemente da direção de dispersão, tendo-se o cuidado de identificar apropriadamente qual posição física no espectro corresponde a um dado comprimento de onda.

Terminada a identificação das linhas espectrais da lâmpada de calibração, passa-se ao reconhecimento das linhas espectrais da fonte de interesse, representada aqui pelo espectro da lâmpada de hélio. Assim, no DS9, clicamos na região de projeção para selecioná-la (Figura 5(a)) e com as setas do teclado a deslocamos apenas verticalmente até a região de dispersão do espectro do hélio, de modo a garantir que a dispersão amostrada seja a mesma da calibração. Seguimos o mesmo procedimento de zoom para identificação das posições em pixel dos picos de emissão luminosa do hélio, e as inserimos na coluna "x [pixel]" vista na Figura 6(h). Automaticamente os valores em comprimento de onda são calculados em " $\lambda[\mathrm{nm}] "$

\subsection{Equação de calibração dos espectros}

O método de calibração espectral proposto neste trabalho se baseia na obtenção de uma equação que se ajuste aos pontos inseridos através do preenchimento da tabela da Figura 6(a), ou seja, uma expressão que converte os valores em píxeis do espectro em valores em comprimento de onda. Utilizamos como referência os picos de emissão do espectro do mercúrio pois este é um tipo de lâmpada comumente encontrada comercialmente, mas que poderia ser substituída outra referência conhecida. Por simplicidade, no aspecto didático, adotamos um modelo linear para o ajuste. O procedimento é acompanhado pela exibição gráfica simultânea, correlacionando a posição espectral instrumental (em píxeis) e física (em nanômetros), conforme os dados são inseridos.

No ajuste linear, o coeficiente angular, $a$, é o parâmetro multiplicativo de conversão entre as grandezas, e o coeficiente linear, $b$, é o parâmetro aditivo para demarcar o início da escala (equação (3p). Logo, ao preenchermos a tabela na planilha eletrônica correspondente, na Figura 6(a), alimentamos o gráfico correlacionando o registro instrumental das linhas da lâmpada de calibração $(\mathrm{Hg})$ e os valores de referência, sobre os quais é automaticamente realizado um ajuste linear (Figura 6(f)). De posse da equação de calibração obtida no ajuste, para obter o valor em comprimento de onda $(\lambda)$ no espectro de interesse, basta inserir o valor instrumental de uma posição da dispersão $(x)$ na equação de calibração (3).

$$
\lambda[n m]=a[n m / p i x] \cdot x[p i x]+b[n m]
$$

$\mathrm{Na}$ planilha isso pode ser feito automaticamente na tabela da Figura 6(h), onde os comprimentos de

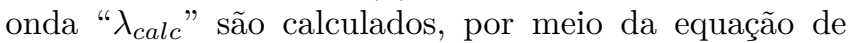

calibração, para o valor de dispersão instrumental do espectro de interesse inseridos na coluna " $\mathrm{x}$ [pixel]".

$\mathrm{Na}$ planilha eletrônica usada nesta atividade existe a possibilidade de usar uma reta de ajuste manual (em vermelho Figura 6(f)) para fins didáticos, pois com ela é possível modificar os valores dos coeficientes angular e linear, auxiliando a explicação do conceito aos estudantes do que significa o "melhor ajuste".

\subsection{Aplicação para o caso do espectro de Hélio}

Com o propósito de ilustrar o procedimento de calibração em comprimento de onda, obtivemos com as etapas descritas na seção 2, um espectro sobrepondo a lâmpada de calibração de mercúrio com uma lâmpada de hélio, cujos comprimentos de onda de interesse referemse às suas linhas espectrais. Esta opção visou facilitar a comparação entre os valores obtidos por meio da calibração e aqueles registrados pelo NIST, conforme os procedimentos na seção 2.3. A equação de calibração obtida por meio dos procedimentos descritos nas seções 3.1 e 3.2 para o espectro de hélio em nosso espectrógrafo caseiro (Figura 2(b)), é dada pela equação (4):

$$
\lambda[n m]=0,1706 \cdot x[p i x]+407,83
$$

sendo que os valores instrumentais para linha de calibração encontram-se na Figura 6(a).

As posições em pixel das linhas espectrais do hélio foram identificadas conforme as etapas apresentadas na Figura 5 Na Tabela 2, resumimos os valores identificados para as posições instrumentais das linhas espectrais do hélio (x [pixel]), o comprimento de onda esperado $\lambda_{H g}$, conforme o NIST, o comprimento de onda calculado, $\lambda_{\text {cacl }}$ em nanômetros, conforme a equação (4) e a raiz quadrática média dos resíduos (RMS), também em nanômetros.

A média da dispersão estatística dos dados (módulo de resíduo) para os valores de $\lambda$ das linhas de hélio foi de 3,6 nm, um resultado comparável ao de redes de difração comerciais de até 300 linhas por milímetro (veja por exemplo em [25]). O módulo de resíduo da média das linhas do hélio $(3,6 \mathrm{~nm})$ é maior que o do mercúrio (0,9 nm), em razão das propagações das incertezas e resíduos sistemáticos ao se generalizar a calibração em comprimento de onda em uma posição do espectro para outra. Apesar disto, a qualidade da calibração se mostra suficiente para discernir uma grande gama de fenômenos, permitindo identificar linhas espectrais e bandas de

Tabela 2: Linhas do $\mathrm{He}$ obtidas a partir da calibração do $\mathrm{Hg}$

\begin{tabular}{lccc}
\hline x[pixel] & $\lambda_{H g}[\mathrm{~nm}]$ & $\lambda_{\text {calc }}[\mathrm{nm}]$ & RMS[nm] \\
\hline 206 & 447,14 & 443,0 & 4,1 \\
480 & 492,19 & 489,7 & 2,4 \\
536 & 501,57 & 499,3 & 2,2 \\
1039 & 587,56 & 585,1 & 2,4 \\
1482 & 667,81 & 660,7 & 7,1 \\
\hline
\end{tabular}


emissão desconhecidas, além de possibilitar a análise da parte contínua dos espectros, em que detalhes da resolução impactam menos a interpretação dos espectros como um todo. Exemplos de aplicação destas análises encontram-se na seção 4 .

\subsection{Procedimento para calibração do espectro bidimensional}

Como o DS9 permite importar imagens em cores e operar no sistema de coordenadas global (do inglês World Coordinate System $=$ WCS), é possível generalizar a calibração em comprimento de onda ao espectro bidimensional no próprio DS9, utilizando um recurso que permite uma rica discussão sobre a formação de cores em uma imagem e a identificação delas no espectro de forma unívoca.

No procedimento de calibração apresentado na seção 3.2 é gerado automaticamente um "Código de Coordenadas WCS do DS9" (Figura 6(d)), registrando os resultados da calibração de modo compatível com o DS9. Assim, continuando no exemplo do espectro do hélio, conforme os resultados obtidos na seção 3.3 devese abrir um novo frame do tipo RGB no DS9 (menu Frame, opção New Frame RGB). Isso automaticamente abrirá a janela com caixas de seleção e exibição de tons vermelho (Red), verde (Green) e azul (Blue) da escala RGB (Figura 7(b)).

Importamos novamente o mesmo espectro utilizado na seção 3.1, que agora poderá ser visualizado em cores (Figura 7(a)). Para facilitar visualização de todo o espectro na janela do DS9 escolhemos a opção Zoom Fit no botão Zoom. Para realizar a calibração do espectro bidimensional acessamos o menu WCS do DS9 e escolhemos a opção WCS Parameters. Isto abre uma nova janela de diálogo (Figura 7(c)), de mesmo nome e com uma série de abas, cada qual com parâmetros que resumidamente permitem fazer operações lineares de conversões de coordenadas em três eixos e cujos significados mais relevantes podem ser vistos em [26].

Em nosso exemplo, o eixo de dispersão é horizontal, o que corresponde a direção 1 , onde o parâmetro CTYPE1 tem que ser preenchido como "Lambda". O parâmetro CRPIX1 corresponde ao pixel de referência para correções aditivas e multiplicativas, coordenada de onde começa a extração do espectro (neste caso o início da coordenada horizontal); a correção aditiva é feita no parâmetro CRVAL1, cujo valor é obtido pelo coeficiente linear do ajuste, determinado pela equação (4) e CDELT1, que corresponde à correção multiplicativa, é dada pelo coeficiente angular da mesma equação. Os demais eixos devem ter seus parâmetros equivalentes preenchidos, mas com os valores iguais a 1, pois não há transformações nestas direções.

Este procedimento pode ser facilitado com a importação de um arquivo com as informações relevantes para calibração. Copiamos a célula da planilha de calibração [16] que contém "Código de Coordenadas WCS do DS9" (Figura 6(d)) e colamos o conteúdo em um arquivo de texto genérico (Figura 7(e)), salvando-o com a extensão wcs (em nosso caso calibHg.wcs).

Para carregarmos o arquivo calibHg.wcs, abrimos, na janela WCS Parameters, o menu File, seguido de Load, a partir de onde procuramos o arquivo. Automaticamente os parâmetros mais importantes para a calibração são preenchidos (Figura $7(\mathrm{c})$ ).

O espectro bidimensional agora está calibrado. Verificamos esse fato na barra de informações da imagem

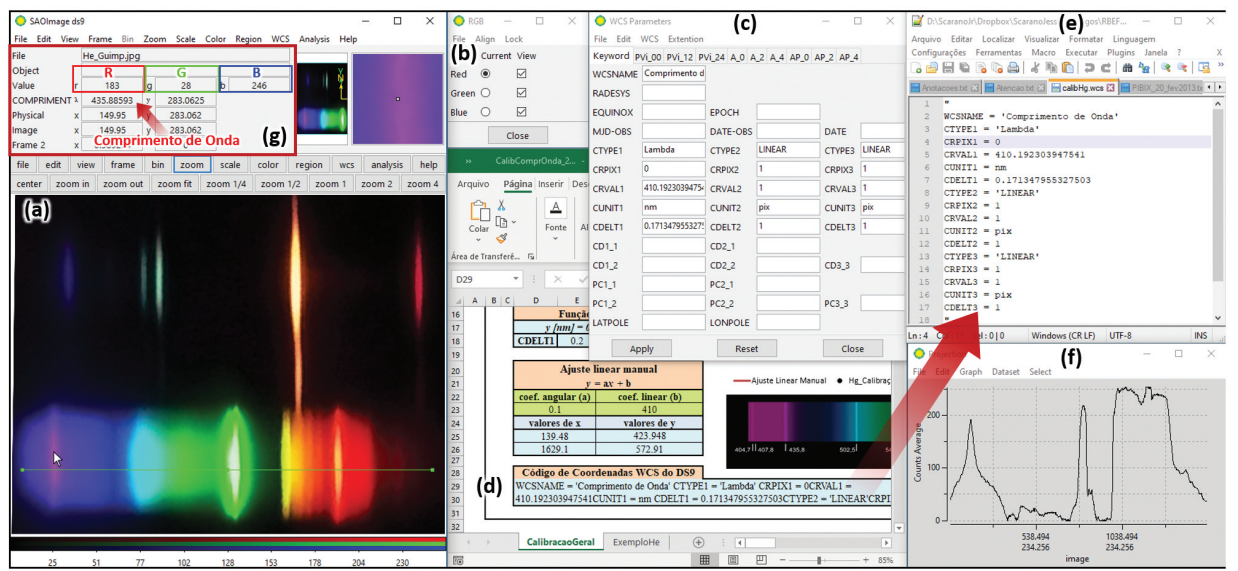

Figura 7: Conjunto de janelas envolvidas no passo de calibração dos espectros bidimensionais em comprimento de onda no DS9. (a) Espectro de calibração para obtenção dos comprimentos de onda das linhas de hélio. (b) Janela de controle das imagens RGB inseridas. (c) Janela para introduzir as correções aditivas e multiplicativas que serão utilizadas para aplicar a calibração em comprimento de onda. (d) Parte da planilha descrita na Figura 6 que contém o texto de palavras-chave apropriadas para calibração bidimensional dos espectros. (e) Arquivo de texto contendo o conteúdo copiado da célula no passo (d) e que deve ser importado na janela WCS Parameters em (c). (f) Exemplo de espectro unidimensional extraído pela ferramenta projection para a cor vermelha no sistema RGB. (g) Seção da barra de informações do DS9 onde o comprimento de onda na posição do cursor no espectro é informado. 
(Figura 7(g)), onde a seção WCS é preenchida com as informações calibradas ao passarmos o ponteiro do mouse sobre a imagem, apresentando na caixa " $\lambda$ " o comprimento de onda na posição indicada pelo ponteiro.

Com esta calibração bidimensional, torna-se possível uma comparação mais direta entre a cor que enxergamos no espectro e um valor numérico único que a representa, ilustrando didaticamente um procedimento físico que permite quantificar grandezas subjetivas.

É possível, a partir dos procedimentos descritos na seção 3.3 extrair um espectro unidimensional do espectro em cores (Figura $7(\mathrm{f})$ ), agora calibrado em comprimento de onda. Infelizmente o espectro não corresponde ao mesmo da Figura 5(b), pois apenas amostra quanto da tonalidade da escala selecionada na janela RGB (Figura 7(b)), ocorre em cada pixel. Esta, juntamente com as outras duas tonalidades, simularão a cor pela combinação de intensidades das três cores do sistema RGB e não pela real emissão da luz em cada comprimento de onda. Note que ao selecionar as demais tonalidades o espectro muda, apresentando as intensidades correspondentes naquela tonalidade, e o carregamento do arquivo de calibração WCS deve ser repetido em cada elemento de cor no Sistema RGB.

Também é possível exportar os espectros unidimensionais, tanto na escala de cores quanto em tons de cinza. Para isso, na janela da Figura 7(f), onde aparece o espectro unidimensional, acessamos o menu File e Save Data, e fornecemos o nome do arquivo do diretório de nosso interesse. O arquivo gerado tem duas colunas, sendo a primeira contendo o eixo, ou seja, a posição em píxeis de onde o fluxo é medido e a segunda o próprio fluxo. Desta forma o arquivo não está calibrado em comprimento de onda, sendo necessário calibrá-lo no software onde se deseja abrir os dados, utilizando a equação (4). Um exemplo do uso destes procedimentos em uma aplicação profissional é a extração de espectros de quasares, que pode ser visto em [27].

\section{Possibilidades Didáticas do Procedimento}

Em termos práticos, diversos aspectos qualitativos e quantitativos dos espectros observados com espectrógrafos caseiros, analisados com os procedimentos de calibração apresentados aqui, podem ser explorados no ensino básico e superior. Um dos primeiros a se destacar, refere-se à identidade espectral dos elementos. As variações de posição e brilho das linhas espectrais de fontes luminosas resultantes da queima de sais em um bico de Bunsen, forneceram originalmente a Gustav R. Kirchhoff as bases para que ele formulasse suas leis para a espectroscopia. Isto impulsionou a análise espectral a partir da constatação empírica de que cada elemento químico possui um espectro único, como uma impressão digital da substância geradora da luz 28. Este mesmo procedimento pode ser reproduzido com a proposta deste trabalho.

Segundo as Leis de Kirchhoff para a espectroscopia: (1) Um corpo em qualquer estado sob alta pressão e aquecido emite um espectro contínuo. Espectroscopicamente isso pode ser demonstrado ao se observar, por exemplo, a luz de uma vela ou uma lâmpada de filamento. (2) Um gás suficientemente aquecido à baixa pressão produz linhas brilhantes, conhecidas como linhas de emissão, em posições características da combinação dos elementos que compõem o gás. Este é o espectro observado em lâmpadas de vapor de mercúrio e de sódio. (3) Um gás de baixa pressão e temperatura que obstrui a luz proveniente de uma fonte de espectro contínuo revela linhas de absorção características da combinação dos elementos que compõem o gás, exatamente nas mesmas posições em que elas ocorreriam se estivessem em condição de emissão. O caso clássico para se verificar isso é por meio da obtenção do espectro solar, seja pela luz do Sol ou da Lua.

A partir destas leis, abriu-se a possibilidade de investigar a composição química e diversas grandezas físicas espectrais do universo em micro e macro escala.

A constatação empírica das leis de Kirchhoff com observações simples, já possui um caráter didático bastante significativo para fundamentar a sua abordagem em física moderna e contemporânea e sua interdisciplinaridade com a Química no ensino básico. Mas este potencial pode ser significativamente aumentado quando focamos nas perspectivas experimentais quantitativas, incluindo o ensino superior, em que experimentos mais sofisticados podem ser propostos.

Adequando os métodos abordados neste trabalho, é possível abordar a determinação das constantes de Rydberg [29] e de Planck [30]. Usando a análise espectral aliada à determinação destas constantes pode-se promover uma discussão mais aprofundada dos primeiros modelos de Bohr para o átomo e o comportamento de fótons e elétrons em transições entre potenciais de energia, o que será explorado em um trabalho futuro.

Apresentamos a seguir algumas possibilidades de aplicações didáticas da metodologia usada neste trabalho.

\subsection{Espectro contínuo e de linha de emissão do sódio}

Antes da apresentação dos espectros de lâmpadas de vapor de sódio e mercúrio, que exemplificam a $2^{\mathrm{a}}$. Lei de Kirchhoff da espectroscopia, pode ser mais ilustrativo iniciar com o espectro de uma lâmpada incandescente ou de uma vela para lidar primeiro com a $1^{\mathrm{a}}$. Lei de Kirchhoff 31.

Ao contrário de lâmpadas incandescentes, que estão ficando cada vez mais raras, a chama de uma vela, é fácil de obter e controlar, podendo ser observada em uma sala de aula ou laboratório. Além disso, ela é uma escolha muito vantajosa no encadeamento didático, pois 


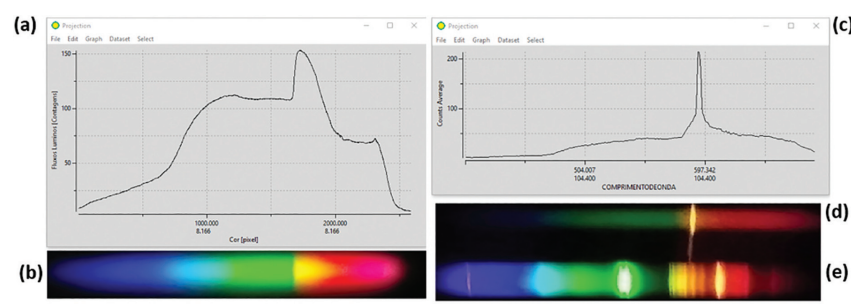

Figura 8: (a) Espectro unidimensional da chama de uma vela, extraído do espectro bidimensional de (b) em unidades relativas. Em (c) está espectro da chama de uma vela mais a linha de sódio, extraído do espectro bidimensional em (d) e calibrado em comprimento de onda utilizando as linhas de mercúrio de uma lâmpada fluorescente compacta (e).

a vela foi a primeira referência para medida de fluxo luminoso, em uma unidade conhecida como candela, tema abordado na atividade proposta por 32 e necessário para entender o conceito de fluxo, além de permitir a demonstração de um dos procedimentos desenvolvidos por Kirchhoff e Bunsen para obtenção dos primeiros espectros: a queima direta de sais de certos elementos.

Com os mesmos procedimentos apresentados na seção 3.1. demonstra-se o que é um espectro contínuo, pela obtenção do espectro unidimensional da luz proveniente apenas da vela, através da ferramenta "projection", destacando o comportamento suave da curva resultante, sem variações bruscas no fluxo luminoso (Figura 8(a)). A pequena elevação entre o verde o amarelo permite discutir interdisciplinarmente questões de Engenharia e Biologia, pois corresponde a uma solução aplicada para a sensibilidade da câmera por meio dos filtros de Bayern [33, 34, de modo a emular a sensibilidade dos cones que permitem a visão humana em cores [35].

Abordando as questões dos limites de sensibilidade da visão do detector e de toda influência que a luz pode sofrer entre a emissão e recepção, é possível gerar uma discussão de forma mais significativa sobre os espectros contínuos da $1^{\mathrm{a}}$. Lei de Kirchhoff, sendo o mais representativo, o de um corpo em equilíbrio termodinâmico: o corpo negro.

Ao submetermos à chama um barbante embebido em água salgada, é notório que a luz emitida se torna mais amarelada. Quando observada através do espectrógrafo, o espectro revela uma linha espectral de emissão intensa, que na verdade se trata de um dubleto do sódio neutro, cujos comprimentos de onda são 588,99 e 589,59 nm [36] (Figura 8(c) e (d)). Independentemente do conhecimento destes valores, com o processo de calibração aqui descrito, foi possível obter o comprimento de onda de $591 \mathrm{~nm}$ da linha de emissão observada na Figura 8(c) e (d). Sendo a dispersão de 2,5 nm, o dubleto se torna indistinguível, mas delimita uma da faixa de incertezas em que valor experimental coincide com os valores esperados para o dubleto.

Tais linhas surgem da vaporização do sódio pela quebra da fraca ligação da molécula de cloreto de sódio, devido ao aquecimento súbito do material, favorecendo a emissão em razão da recuperação de um elétron pelo sódio e de sua desexcitação. Isto ilustra a $2^{\mathrm{a}}$. Lei de Kirchhoff, fornece a oportunidade para quantificar a identidade espectral de um elemento pelo comprimento de onda de suas linhas, e, como veremos na seção 4.4 se conecta com a $3^{\mathrm{a}}$. Lei de Kirchhoff, promovendo aos alunos a experiência de como é possível saber a composição química de objetos astronômicos apenas pela luz destes.

\subsection{O espectro do laser}

Além do fluxo e do comprimento de onda das linhas mencionados neste trabalho, uma questão quantitativa de interesse refere-se à resolução espectral, ou seja, a capacidade de distinguir dois comprimentos de ondas próximos, como nos exemplos do dubleto de NaI [589 e $590 \mathrm{~nm}]$ e $\mathrm{Hg}$ [577 e $579 \mathrm{~nm}$ ].

Há diversos fatores que promovem o alargamento das linhas espectrais, ademais do alargamento natural, como por exemplo: o aquecimento do gás; diferenças em sua pressão; a presença de campos magnéticos; a existência de contaminantes com elementos cujos níveis energéticos são próximos; a sobreposições de condições de excitação e ionização etc. Estes efeitos são tão importantes que são usados para explorar a física atômica/nuclear, no estudo da química de moléculas, com a espectroscopia do tipo Raman; nas transições hiperfinas da espectroscpia Mössbauer; na determinação de diversas grandezas astrofísicas, como a temperatura de gases ou campos magnéticos das manchas solares; até na medicina, com o uso do ultrassom Doppler [37].

O limite de resolução espectral, além de se tornar evidente na abordagem estatística apresentada em nosso procedimento, pode ser explorado como exercício não só na determinação do comprimento de onda de feixes de laser, mas também a largura à meia altura de seus comprimentos de onda de emissão.

Um laser (light amplification by stimulated emission of radiation) é constituído de uma fonte de luz monocromática, coerente e colimada, gerando um espectro de raia única e estreita como na Figura 9 Utilizando o procedimento detalhando em [1], a calibração espectral permitiu a identificação dos comprimentos de onda destes dois lasers como sendo 535,1 nm e uma largura de 2,6 nm para o laser verde e 651,2 nm e largura de 3,2 $\mathrm{nm}$ para o laser vermelho de laser pointers comumente encontrados no mercado. Estes valores corresponderam perfeitamente aos valores informados nas embalagens, dentro da margem das incertezas da calibração $(3,0 \mathrm{~nm})$.

\subsection{Telas de celular e TVs de LCD e LED}

As telas e monitores estão presentes no cotidiano nas mais variadas atividades. Compreender o funcionamento destes dispositivos pode ser um elemento motivador 


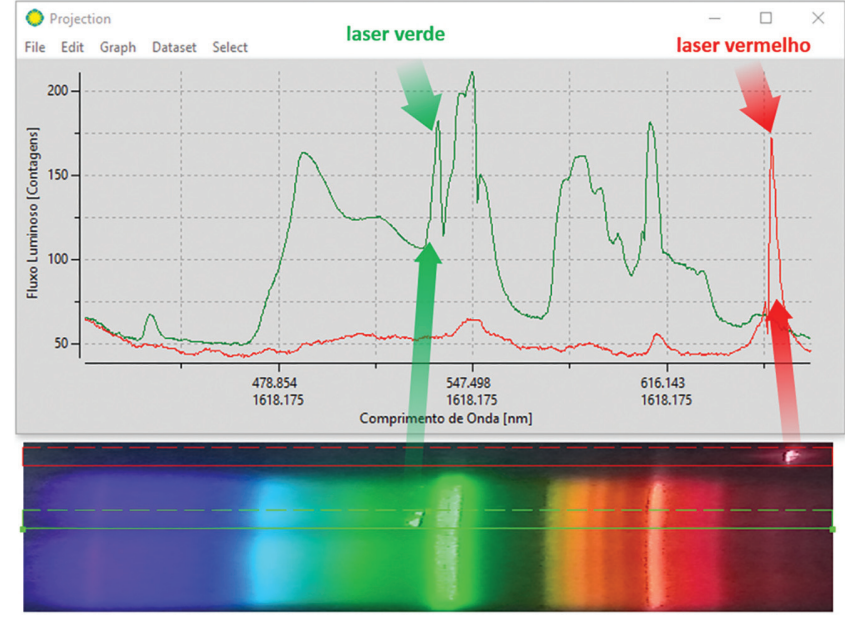

Figura 9: Espectro unidimensional e bidimensional do feixe de um laser verde e vermelho proveniente de laser pointers comerciais sobrepostos ao espectro de uma lâmpada fluorescente de mercúrio.

do ensino de Física, carregado de interdisciplinaridade, especialmente com a Biologia, a Química e a Engenharia.

O estudo do espectro de telas permite compreender o processo de formação de imagens, discutir a natureza física dos elementos químicos usados no processo de dopagem dos LEDs, para que tenham distintas características luminosas, além de permitir explorar a tecnologia abarcada e a engenharia de materiais utilizados na construção destes dispositivos.

O processo pelo qual os LEDs emitem luz é chamado de eletroluminescência e a luz emitida por eles não é estritamente monocromática, podendo se estender por um conjunto de cores próximas entre si, denominadas banda de emissão, estrategicamente concebidas para terem uma certa sobreposição espectral. Este processo faz com que a emissão espectral dos LEDs seja significativamente mais larga que as linhas de emissão de um gás aquecido. Com a miniaturização destes componentes eletrônicos e o processo de engenharia para gerar matrizes destes elementos microscópicos independentes e coordenados de emissão de luz, geometricamente dispostos para se sobreporem dentro de um certo limite resolução angular, é possível em escala macroscópica, formar imagens.

Em analogia com muitos fenômenos físicos, a obtenção de espectros de diferentes tipos de telas permite explorar a combinação de propriedades físicas simples, a exemplo da posição e intensidade luminosa dos LEDs, possibilitando uma grande diversidade de formas e cores em telas. Esta atividade é abordada em [35].

Na Figura 10, é apresentado o espectro de uma tela de TV de LED exibindo uma imagem branca, de forma tal que as bandas de emissão dos LEDs que compõem seus píxeis físicos se tornam aparentes, de acordo com as três cores do sistema RGB.

Verificamos, utilizando a ferramenta "projection" do DS9, o comprimento de onda do centro fotométrico das
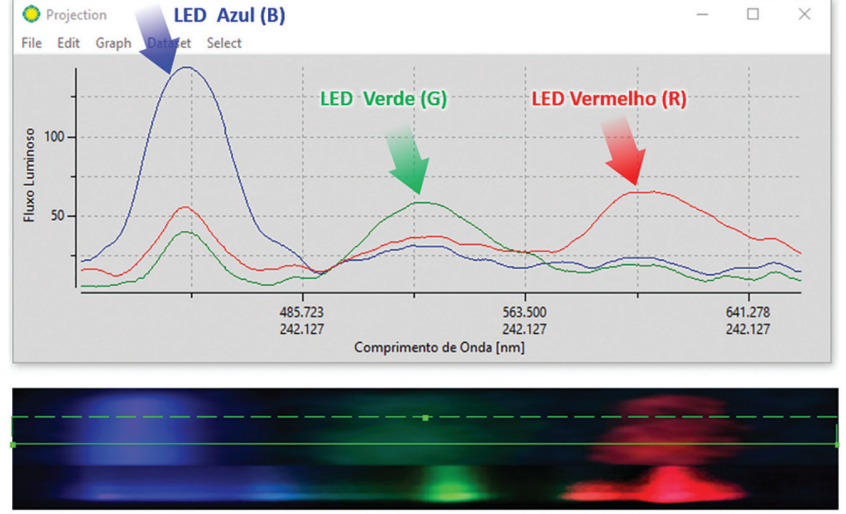

Figura 10: Espectro unidimensional e bidimensional dos LEDs de uma TV de LED utilizando o espectro de uma lâmpada de mercúrio para calibração. As cores foram separadas por meio dos procedimentos na seção 3.4

bandas de emissão do espectro observado. Para os LEDs azul, verde e vermelho os comprimentos de onda foram $446( \pm 20) \mathrm{nm}, 535( \pm 36) \mathrm{nm}$ e $600( \pm 27) \mathrm{nm}$ respectivamente, sendo os valores entre parênteses as estimativas das larguras de banda. Infelizmente, por se tratar de uma tecnologia protegida, as produtoras dos aparelhos não divulgam estes valores para que possam ser comparados, mas os valores são compatíveis marginalmente com os valores típicos de LEDs comerciais em suas respectivas cores.

A discussão apresentada neste trabalho sobre o sistema RGB pode ser aprofundada em termos quantitativos, ao se propor a estimativa dos fluxos em cada banda, utilizando regiões retangulares do DS9. A partir delas há um recurso para determinar as estatísticas dentro de cada região amostrando uma banda diferente. Assim, variando-se as cores nas telas, pode-se determinar o fluxo em cada banda de emissão, relativo à intensidade máxima quando a tela está branca, de modo a obter a combinação de fluxos em cada banda que gera a cor exibida nas telas.

Uma conexão didática importante, em associação com a Biologia, é a que permite discutir a relação das medidas feitas pelos espectros e os efeitos da produção do hormônio melatonina e o ciclo circadiano. Igualmente produtiva e ligada à observação dos espectros de LEDs, do sódio e do mercúrio é uma atividade relacionada à Astronomia Observacional para debater a questão da poluição luminosa.

\subsection{O espectro solar e as linhas de Fraunhofer}

A observação da luz solar constitui a fonte mais simples para apresentar experimentalmente a $3^{\mathrm{a}}$. Lei de Kirchhoff por meio das linhas de Fraunhofer e, portanto, é muito representativa de atividades que envolvam a espectroscopia. Apesar de teoricamente constituir uma observação simples, pela abundância de fótons 


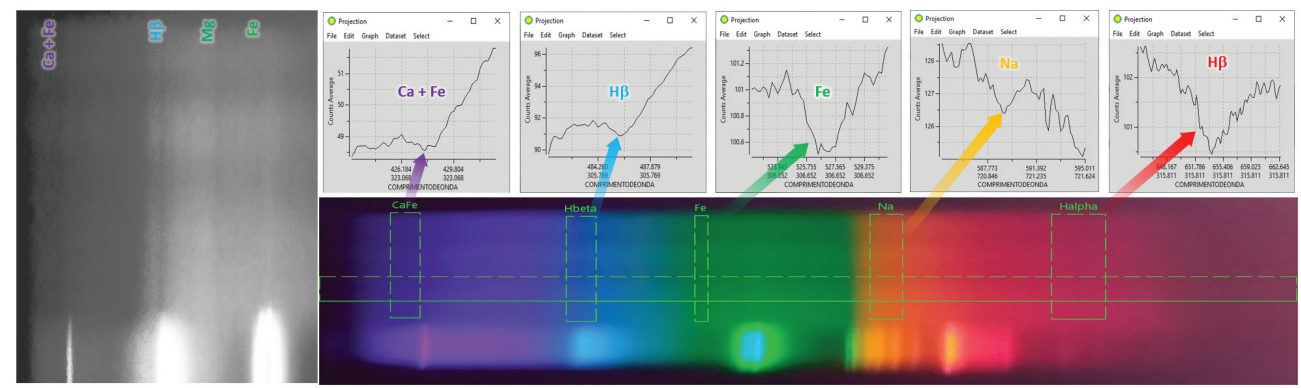

Figura 11: À esquerda, em torno da linha de $\mathrm{H} \beta$, espectro bidimensional do Sol refletido em uma parede, realçado pelo zoom e o contraste no DS9. À direita os espectros unidimensionais das linhas reconhecidas com o espectro em cores para indicar as posições das identificações.

provenientes da fonte, a obtenção do espectro pode ser cheia de truques e relativamente perigosa quando não se possui recursos especiais para o registro espectral, como uma câmera digital profissional [8] ou um CCD. Na atividade aqui proposta não há risco com a observação do Sol e nenhum requisito especial de câmera é necessário para obtenção dos espectros.

Assumimos os mesmos procedimentos para obtenção de espectros calibráveis mencionados na seção 2.1 e, ao invés de uma observação direta Sol (perigosa para a visão do observador), optamos por utilizar a luz do Sol refletida em uma parede, ou qualquer anteparo branco. Com isso, ainda que com câmeras de celulares simples, é possível registrar os espectros. Mesmo as linhas que não são facilmente observadas diretamente no espectrógrafo, passam a ser facilmente identificadas com o DS9. O principal problema que diferencia o espectro observado diretamente no espectrógrafo e o registrado por meio de imagens, está na limitação de foco da câmera e na vibração e flexão tanto do espectrógrafo quanto da câmera, conforme os espectros são obtidos.

Para resolver a questão do foco basta controlar a distância do elemento dispersor e da câmera, enquanto flexões podem ser evitadas ao se apoiar o espectrógrafo sobre uma superfície em que se possa direcionar a fenda do espectrógrafo para luz refletida do Sol. Quando as opções da câmera permitem o controle manual das opções de tempo de exposição, ISO e foco, a qualidade dos espectros obtidos pode ser melhorada, mas aqui assumimos a situação de configurações automáticas, como é o caso da maioria das câmeras digitais.

Ao invés de partir do espectro unidimensional, neste caso específico, a inspeção visual do espectro bidimensional, gerado pelos procedimentos da seção 3.4 pode facilitar o reconhecimento de linhas espectrais, que apresentam absorção com fluxo ligeiramente inferior ao do contínuo, e, portanto, com baixo contraste. Assim, variando-se o nível de contraste e o nível de zoom do espectro utilizando-se os recursos do botão direito e da roda do mouse no DS9, é possível identificar visualmente as linhas de absorção (à esquerda na Figura 11 . em tons de cinza). Fazendo-se extrações individuais com regiões de projeção do DS9 no entorno destas regiões e aumentando-se a espessura da região traçada, o sinal dentro da região é estatisticamente integrado, destacando nos espectros unidimensionais as linhas de absorção reconhecidas (gráficos na Figura 11).

A dispersão da calibração utilizando a lâmpada de mercúrio foi de $2,3 \mathrm{~nm}$, enquanto a posição das linhas reconhecidas apresentou uma dispersão inferior a 2,0 nm, utilizando as linhas $\mathrm{Ca}+\mathrm{Fe}[430 \mathrm{~nm}], \mathrm{H} \beta$ [486 nm], $\mathrm{Fe}[527 \mathrm{~nm}], \mathrm{Na}[590 \mathrm{~nm}]$ e $\mathrm{H} \alpha$ [656 nm], que correspondem às designações de Fraunhofer $\mathrm{G}$ (mescla de dois elementos), F, $\mathrm{E}_{2}, \mathrm{D}_{1}+\mathrm{D}_{2}$ (mescla de linhas de um único elemento) e $\mathrm{C}$ respectivamente.

O mesmo procedimento aplicado ao espectro da Lua permite uma demonstração sofisticada do caráter iluminado da Lua, desmistificando uma série de teorias conspiratórias sobre a natureza de nosso satélite. Também permitem a verificação de que o material que compõe o Sol tem a mesma natureza que da Terra. Isso pode ser feito especialmente por meio de desafios para se obter espectros de melhor qualidade e identificar as linhas de absorção do $\mathrm{Hg}$ [546 nm] e do $\mathrm{Na}$ [590 nm], que se encontram nas mesmas posições no espectro de emissão do mercúrio e da vela com a vaporização do sódio, observados na Terra.

\section{Conclusões}

Apesar da subjetividade da cor que enxergamos, é possível quantificá-la de modo a atribuir um valor numérico a ela, como a frequência e o comprimento de onda. Essas "medidas da cor", foram abordadas neste trabalho, que teve como principal objetivo a apresentação de um método de calibração espectral simples que conta com o auxílio do programa DS9 e uma planilha eletrônica. Utilizamos um espectroscópio de baixo custo, que acoplado com a câmera de um celular pode ser transformado em espectrômetro, capturando os espectros que podem ser posteriormente processados e analisados. Seguindo a metodologia proposta de obter os espectros de interesse juntamente com a luz proveniente de uma lâmpada de calibração, apresentamos um exemplo ilustrativo em que determinamos os comprimentos de onda de uma lâmpada de hélio calibrada a partir de uma 
lâmpada compacta de mercúrio comercial. Utilizando uma planilha eletrônica como recurso para registrar os dados e calcular a equação de calibração e por um modelo linear simples, obtivemos uma média dos resíduos de 0,9 nm para as linhas do mercúrio e 3,6 nm para as do hélio, compatível os resultados de redes de difração comerciais de até $300 \mathrm{l} / \mathrm{mm}$.

Ademais do método de calibração, apresentamos alguns exemplos de aplicações, com discussões em torno das leis de Kirchhoff para espectroscopia, ao longo das quais são feitas algumas sugestões sobre como abordar os experimentos citados.

Acreditamos que uma análise quantitativa reforça o caráter mais preciso dos conceitos associados à luz, o que permite estabelecer um critério objetivo sobre a noção de cor, que numa análise puramente qualitativa, depende de questões subjetivas. Optamos por procedimentos e análises simples, mas com grandes possibilidades de temas a serem abordados, de modo que este experimento pode ser usado desde o ensino médio, até aulas experimentais em universidades.

Espectros produzidos com os procedimentos apresentados, são constantemente atualizados em nosso repositório, o que facilita o acesso e a realização dos experimentos aqui abordados, pois alguns deles podem ser particularmente custosos, para serem obtidos de forma caseira. Trabalhos futuros com o espectrômetro usado incluem a calibração em fluxo, que permitirá explicar as probabilidades de transições eletrônicas que geram as raias espectrais, dependendo da energia original da fonte de excitação e o conceito de temperatura de cor, o que permitirá promover ações de interdisciplinaridade entre a Química, Física Moderna e Astrofísica.

Os materiais e métodos aqui disponibilizados constituem um recurso muito conveniente para aplicação de atividades práticas remotas e para o ensino a distância (EAD), além de serem completamente compatíveis com as diretrizes da nova Base Nacional Comum Curricular para o Ensino Médio (BNCC), dado seu grande potencial no contexto do ensino investigativo interdisciplinar. Assim, as ações propostas neste trabalho podem conduzir os alunos a uma postura mais questionadora e curiosa sobre a Física e a sua relação com elementos cotidianos, saindo da esfera da abstração para observação de conceitos de forma prática, fortalecendo as bases para uma educação científica crítica e capaz de gerar impacto na estrutura cognitiva do estudante.

\section{Referências}

[1] P.J. Santos e S. Scarano Jr, em: Ensino de Física: do Olhar à Prática, editado por D.N. Souza (Editora da UFS, São Cristóvão, 2019).

[2] F. Wakabayashi e K. Hamada, J. Chem. Educ. 83, 56 (2006).

[3] D.O. Leite e R.J. Prado, Rev. Bras. Ens. Fís. 34, 2504 (2012).
[4] L.G. Barros, A. Assis e R. Langhi, Cad. Bras. Ens. Fís. 33, 1026 (2016).

[5] H.J. Kalinowski e N.D. Garcia, Caderno Catarinense de Ensino de Física 7, 64 (1990).

[6] N.D. Garcia e H.J. Kalinowski, Caderno Catarinense de Ensino de Física 11, 134 (1994).

[7] Y. Kraftmakher, Phys. Educ 47, 184 (2012).

[8] A.L. Xavier Jr, Cad. Bras. Ens. Fís. 34, 621 (2017).

[9] E.G. Szigety, L.J. Bernal, L. Bilbao e G.H. Pérez, Cad. Bras. Ens. Fís. 37, 263 (2020).

[10] X. Bian, P. Diwu, Y. Liu, P. Liu, Q. Li e X. Tan, J. Chemom. 32, e2940 (2018).

[11] G.J. Long e F. Grandjean, Mössbauer spectroscopy applied to inorganic chemistry (Springer Science \& Business Media, New York, 2013), v. 3.

[12] J.R. Moffitt, Y.R. Chemla, S.B. Smith e C. Bustamante, Annu. Rev. Biochem 77, 205 (2008).

[13] J.G. Williams, S.G. Turyshev e D.H. Boggs, Int. J. Mod. Phys. D 18, 1129 (2009).

[14] P.R. Carey, J Biol Chem 274, 26625 (1999).

[15] M.T. Murphy, T. Udem, R. Holzwarth, A. Sizmann, L. Pasquini, C. Araujo-Hauck, H. Dekker, S. D'Odorico, M. Fischer, T.W. Hänsch et al., Monthly Notices of the Royal Astronomical Society 380, 839 (2007).

[16] https://github.com/JSantosSScaranoJr/Santos_Scara noJr_2021_RBEF.git

[17] E. Angel, e D. Shreiner, Interactive computer graphics: a top-down approach with shader-based Open GL (AddisonWesley, Boston, 2012).

[18] https://youtu.be/4ojEY_omC8c, acessado em 20/01/2020.

[19] https://physics.nist.gov/PhysRefData/ASD/lines_for m.html, acessado em 05/05/2020.

[20] J.F. Pavon, W.F.P. Neves-Junior, M.A. Spiropulos e D.B. Araújo, Rev. Bras. Ens. Fís. 36, 4501 (2014).

[21] F. Savall-Alemany, J.L. Domènech-Blanco e J. MartínezTorregrosa, Rev. Bras. Ens. Fís. 36, 4302 (2014).

[22] https://www.lighting-gallery.net/gallery/displayimage. php?album $=3248 \&$ pos $=8 \&$ pid $=1335866$, acessado em $29 / 07 / 2020$

[23] S. Scarano Jr, Manual de Utilização do Programa DS9, disponível em: http://www.telescopiosnaescola.pro.br /manual_ds9.pdf, acessado em 20/01/2020.

[24] https://youtube.com/playlist?list=PLgcih4NzmK425 yH96wYYaAhLlyQw_KZ0k, acessado em 17/03/2021.

[25] https://andor.oxinst.com/resolution-calculator. acessado em 03/03/202.

[26] S. Scarano Jr, R.L. Oliveira Filho, I.S. Mitaraquis, R.A. Silva e V.R. Cruz, disponível em: http://scaranojr.com. br/Extensao/PIBIX2014/Espectroscopia/Espectroscopi a\%20.pdf, acessado em 21/07/2020.

[27] https://youtu.be/Ra-UBjH4cJM, acessado em 21/07/2020.

[28] L.O.Q. Peduzzi, Do átomo grego ao átomo de Bohr, disponível em: https://www.if.ufrgs.br/ lang/Text os/Textos_Peduzzi/Atomo_grego_Bohr.pdf, acessado em 19/03/2020.

[29] P. Onorato, M. Malgieri e A. De Ambrosis. Eur. J. Phys. 36, 058001 (2015). 
[30] M.R.A.S.F. André e P.S.B. André, Classroom fundamentals: measuring the Planck constant, disponível em: http://www.scienceinschool.org/2014/issue28/planck acessado em 12/09/2020.

[31] J.P. Santos, Aprendizagem cooperativa: estudando conceitos físicos de cor e espectro através da astronomia. Dissertação de Mestrado, Universidade Federal de Sergipe, São Cristóvão (2018).

[32] E.F. Santos, Variáveis Cefeídas e a Contribuição Feminina na Ciência: Recursos Para O Ensino De Oscilações, Ondas E Óptica. Dissertação de Mestrado, Universidade Federal de Sergipe, São Cristóvão (2017).

[33] V. Lebourgeois, A. Bégué, S. Labbé, B. Mallavan, L. Prévot, e B. Roux, Sensors 8, 7300 (2008).

[34] P.A. Cheremkhin, V.V. Lesnichii e N.V. Petrov, J. Phys.: Conf Ser. 536, 012021 (2014).

[35] J.P. Santos e S. Scarano Jr, Cores em monitores: Identificando os comprimentos de onda da luz na tela de um monitor $L C D$ e de uma TV de LED através de um espectrógrafo caseiro (Editora da UFS, São Cristóvão, no prelo).

[36] A. Kramida, Y. Ralchenko, J. Reader e NIST ASD Team (2019), NIST Atomic Spectra Database, v5.7.1, acessado em 24/08/2020: https://physics.nist.gov/asd.

[37] G. Guidi, C. Licciardello e S. Falteri, Ultrasound Med. Biol. 26, 853 (2000). 